\title{
Neonatologia em
} bezerros: a importância do colostro

\section{Neonatology in calves: the importance of colostrum}

\section{Resumo}

Os neonatos são capazes de responder a agentes infecciosos por meio das respostas imune inata e adquirida, no entanto, estas são lentas, de pequena magnitude e com baixas concentrações de anticorpos. Dessa forma, a transferência materna da imunidade é fundamental para a sobrevivência inicial do bezerro, pois fornece ao neonato bovino anticorpos, células do sistema imunológico e outros elementos essenciais à sua sobrevivência, como nutrientes, componentes do sistema complemento, fatores de crescimento, hormônios, citocinas, oligossacarídeos, gangliosídeos, reativos de oxigênio, proteínas de fase aguda, fatores imunomoduladores, enzimas, ribonucleases, nucleotídeos, poliaminas, peptídeos e proteínas com atividade antimicrobiana, antioxidantes e inibidores de tripsina. Nesta revisão, são discutidos os vários aspectos e características da transferência de imunidade no pós-parto e da neonatologia em bezerros, enfatizando a importância da ingestão do colostro.

\section{Abstract}

Neonates are able to respond to infectious agents by their innate and acquired immune responses, however, they are slow, produced in small-scale and have low antibody concentrations. Thus, maternal immunity transference is critical to calf initial survival, since it provides antibodies to the neonate bovine, cells of the immune system, as well as other essential elements to its survival, as nutrients, components of the complement system, growth factors, hormones, cytokines, oligosaccharides, gangliosides, reactive oxygen molecules, acute phase proteins, immunomodulatory factors, enzymes, ribonucleases, nucleotides, polyamines, peptides and proteins with antimicrobial activity, antioxidants and trypsin inhibitors. This review presents a discussion of different aspects and characteristics of immune transference in postcalving and neonatology to calves, emphasizing the colostrum feeding importance. 
Guilherme Alves Guerra ${ }^{1}$

Elaine Maria Seles Dorneles ${ }^{1}$

Fernando Nogueira Souza ${ }^{4}$

Adriana Cortez ${ }^{3}$

Camila Freitas Batista ${ }^{4}$

Sandra Gesteira Coelho ${ }^{2}$

Andrey Pereira Lage 1

Alice Maria Melville Paiva Della Libera ${ }^{4}$

Marcos Bryan Heinemann ${ }^{5}$
Avenida Prof Dr Orlando Marques de Paiva, 87, Cidade Universitária, São Paulo/SP, CEP: 05508-270

西arcosbryan@usp.br

\section{Palavras-chave}

Bovinos. Criação de bezerros. Colostro.

Imunidade passiva.

Keywords

Bovines. Cattle. Colostrum. Passive immunity.

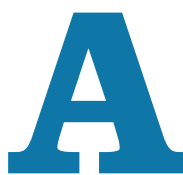

pesar de os neonatos serem capazes de responder a agentes infecciosos por meio das respostas imune inata e adquirida, estas são lentas, de pequena magnitude e com baixas concentrações de anticorpos. Assim, a ingestão e a absorção de quantidades adequadas de imunoglobulinas presentes no colostro são condições essenciais para o estabelecimento da imunidade do bezerro, até que o seu sistema imune se torne completamente funcional. A formação do colostro ocorre no período pré-parto e é influenciada por fatores hormonais sistêmicos e locais. Além disso, a qualidade da transferência de imunidade passiva ao bezerro neonato é influenciada pelo momento da ingestão de colostro, como também pelo método e volume de sua administração, pela concentração de imunoglobulina existente no colostro ingerido e pela idade da mãe. Nesta revisão, são discutidos aspectos e características da transferência de imunidade passiva no pós-parto e da neonatologia em bezerros, ressaltando a importância da formação e composição do colostro.

\footnotetext{
1 Universidade Federal de Minas Gerais, Escola de Veterinária, Departamento de Medicina Veterinária Preventiva, Belo Horizonte/MG, Brasil.

2 Universidade Federal de Minas Gerais, Escola de Veterinária, Departamento de Zootecnia, Belo Horizonte/MG, Brasil.

3 Universidade de Santo Amaro, Curso de Medicina Veterinária, São Paulo/SP, Brasil.

4 Universidade de São Paulo, Faculdade de Medicina Veterinária e Zootecnia, Departamento de Clínica Médica, São Paulo/SP, Brasil.

5 Universidade de São Paulo, Faculdade de Medicina Veterinária e Zootecnia, Departamento de Medicina Veterinária Preventiva e Saúde Animal, São Paulo/SP, Brasil.
} 


\section{Sistema imunológico}

O sistema imunológico dos mamíferos domésticos composto por barreiras físicas, solúveis e celulares, que permitem ao organismo sobreviver a diversos tipos de agressões provenientes, inclusive, de agentes infecciosos - é constituído pelo sistema imune inato ou natural (SIN) e pelo sistema imune adquirido ou adaptativo (SIA), entretanto, a delimitação desses dois componentes é extremamente difícil, pois ambos compartilham sistemas e mecanismos efetores da resposta imune. O SIN compreende mecanismos pré-existentes que não dependem de estímulos para ser ativado, mas quando é estimulado apresenta alterações quantitativas, com aumento do número de células e a expressão de citocinas e quimiocinas. O SIN, constituído por barreiras físicas, mecânicas e biológicas, que atuam como primeira linha de defesa, responsável pela prevenção de replicação, morte ou redução do número inicial de microrganismos, também é capaz de criar condições para a geração de uma resposta imune adaptativa eficaz (DIACOVICH; GORVEL, 2010). Um exemplo que diferencia os dois sistemas é que o inato reconhece padrões moleculares associados a patógenos, como lipopolissacarídeos (LPS), peptideoglicanos e flagelinas, enquanto o SIA reconhece proteínas específicas de um determinado patógeno (KINDT; GOLDSBY; OSBORNE, 2007). Outras características do SIA incluem: dependência de células especializadas, especificidade, memória, diversidade para reconhecimento dos diferentes determinantes antigênicos, autolimitação e tolerância aos componentes do próprio organismo.

A evolução do sistema imune, nos mamíferos domésticos, inicia-se na vida fetal com o surgimento dos órgãos linfoides primários (por exemplo, timo e medula óssea) e secundários (por exemplo, baço e linfonodos) (TIZARD, 2013), e geralmente quanto mais curta é a gestação, menos desenvolvido é o sistema imune quando do nascimento (CORTESE, 2009). Esse desenvolvimento segue determinado padrão, no qual o timo é o primeiro órgão linfoide a se desenvolver, seguido dos órgãos linfoides secundários, como baço e linfonodos. No bezerro, o timo é detectado aos 40 dias de gestação, a medula óssea e o baço aos 55, os linfonodos aos 60, e as placas de Peyer aos 175 dias (TIZARD, 2013).

No timo, ocorre o desenvolvimento e a diferenciação dos timócitos em linhagens celulares. A linhagem de células-tronco possui clusters of differentiation (CD) 7 e 34 e irá se rearranjar nas células pré-T, positivas para os CD 1, 4, 5, 7 e 8. Nos tecidos linfoides secundários, essas células se diferenciam em células T CD 1, 3, 5, 7 e 8 (linfócitos T supressor, ativados e citotóxico), e CD 2, 3, 4, 5, 7 (linfócitos auxiliar, indutor e ativado) positivas (CORTESE, 2009;
GEENEN et al., 2001). Na medula óssea fetal, as células B se desenvolvem e se diferenciam em subpopulações: a célula B tronco apresenta em sua superfície o $\mathrm{CD} 34$, a célula pré $\mathrm{B}$ os CD 10, 19, 20, 24 e 38, e a célula B no tecido linfoide os CD 19, 20, 21, 22, 24, 38 (GEENEN et al., 2001).

À medida que a gestação progride, há um aumento progressivo dos linfócitos periféricos, majoritariamente linfócitos T (CORTESE, 2009). Um mês antes do parto, os linfócitos T começam a migrar e a povoar os tecidos linfoides fetais (CHASE; HURLEY; REBER, 2008). Ao mesmo tempo, há o desenvolvimento e a distinção de outras populações de leucócitos, tais como macrófagos, neutrófilos e células natural killer (NK) (CORTESE, 2009).

A capacidade de o feto bovino produzir anticorpos pode ocorrer a partir dos 75 dias de gestação e indica a ocorrência de uma infecção intrauterina. De forma geral, os fetos são agamaglobulinêmicos, mas nas infecções intrauterinas eles desenvolvem uma resposta com a produção de anticorpos. Nessa resposta imunológica, as imunoglobulinas (Ig) da classe M (IgM) são predominantes, no entanto, em menor concentração do que a observada na resposta gerada pelo animal maduro (CHASE; HURLEY; REBER, 2008).

Apesar de todos os componentes celulares da resposta imune adquirida estarem presentes durante a vida fetal, o feto bovino é protegido principalmente pelo SIN, por meio das células fagocíticas, como neutrófilos e macrófagos (CHASE; HURLEY; REBER, 2008; CORTESE, 2009). Durante o nascimento dos bezerros, ocorre a transferência de microbiota vaginal da mãe para o feto, o que contribui para o desenvolvimento da microbiota do trato gastrointestinal do bezerro e para a imunidade das mucosas (TASCHUK; GRIEBEL, 2012).

Os neonatos se deparam com um ambiente rico em microrganismos e são capazes de responder a esses agentes por meio das respostas imune inata e adquirida, porém, essas respostas são lentas, de pequena magnitude e com baixas concentrações de anticorpos (TIZARD, 2013). Dessa forma, a transferência materna da imunidade é fundamental para a sobrevivência inicial do bezerro (STELWAGEN et al., 2009).

\section{Transferência de imunidade passiva}

A placenta dos bovinos é a do tipo sindesmocorial, caracterizada por apresentar um sincício entre o endométrio maternal e o trofoblasto fetal (PETER, 2013), que impede o encontro do sangue da vaca e do feto e, consequentemente, a transmissão intrauterina de Ig (GODDEN, 2008; PETER, 2013; TIZARD, 2013). Dessa forma, o bezerro nasce agamaglobulinêmico e o seu sistema imune ainda não é capaz de produzir anticorpos em quantidades necessárias para o combate das infecções (PETER, 2013; TIZARD, 
2013). Portanto, a ingestão e a absorção de quantidades adequadas de imunoglobulinas presentes no colostro são condições essenciais para o estabelecimento da imunidade do bezerro, até que o seu sistema imune se torne completamente funcional (GODDEN, 2008; TIZARD, 2013). O monitoramento da quantidade de imunoglobulinas absorvidas pelo bezerro pode ser efetuado até o segundo dia de vida do animal, com o emprego de um refratômetro que mede as proteínas totais no soro ou com a utilização de kits específicos para dosagem de Ig (BAUMRUCKER et al., 2010; KEHOE; JAYARAO; HEINRICHS, 2007).

A absorção das Ig e de leucócitos maternais durante as primeiras horas de vida via colostro é chamada de transferência passiva de imunidade e ajuda a proteger o neonato de diversos patógenos. Os fatores que influenciam a transferência de imunidade passiva ao bezerro neonato são: $o$ momento da ingestão de colostro, o método e o volume de colostro administrado, a concentração de imunoglobulina no colostro ingerido e a idade da mãe (WEAVER et al., 2000). Nas primeiras 24 a 36 horas pós-parto, a absorção das imunoglobulinas e células presentes no colostro é bem-sucedida, no entanto, a maior quantidade ocorre nas primeiras 24 horas pós-nascimento e particularmente nas primeiras seis horas pós-parto (BRANDON; LASCELLES, 1971). Baseando-se no que ocorre naturalmente, quando o bezerro mama o colostro direto da vaca e no reflexo de sucção que leva ao fechamento da goteira esofágica, foi constatado que a administração do colostro em mamadeiras (reflexo de sucção presente) é superior a outras formas de administração (BESSER; GAY; PRITCHETT, 1991).

No entanto, a quantidade ingerida e a concentração de imunoglobulinas presentes no colostro são mais importantes do que a forma utilizada para a sua administração (WEAVER et al., 2000). A quantidade de colostro a ser ingerida está diretamente ligada à quantidade de imunoglobulinas presentes, sendo que um colostro de boa qualidade deve fornecer pelo menos 100 gramas de IgG ao neonato, entretanto, foi observado que apenas $36 \%$ dos colostros analisados fornecem a massa adequada de IgG quando fornecidos na quantidade de dois litros (BESSER; GAY; PRITCHETT, 1991). Como a diferenciação entre colostros com alta ou baixa concentração de imunoglobulinas não é rotineiramente utilizada, a alternativa mais recomendada é a de permitir que o bezerro mame o colostro diretamente da mãe, o que parece minimizar o problema da quantidade de IgG ingerida (BESSER; GAY; PRITCHETT, 1991; WEAVER et al., 2000), contudo, essa prática não significa que o bezerro está bem colostrado.

Além disso, embora controverso, também foi demonstrado que as vacas de terceira lactação possuem maior concentração de IgG no colostro do que as de primeira ou segunda lactação (MULLER; ELLINGER, 1981). O aumento de IgG no colostro ocorre no máximo até o terceiro ou quarto parto (MULLER; ELLINGER, 1981). A proteção conferida pelo colostro, baseada em uma proteção imune sistêmica e gastrointestinal, além de determinar a redução da mortalidade no período pós-desmama, também promove melhor taxa de ganho de peso e eficiência alimentar, redução da idade ao primeiro parto, melhoria da produção de leite da primeira e segunda lactação, além de redução da tendência para abate durante a primeira lactação (GODDEN, 2008; HURLEY; THEIL, 2011; STELWAGEN et al., 2009).

\section{Composição do colostro}

O colostro é definido como a primeira secreção da glândula mamária após o parto (CORTESE, 2009) e consiste na mistura de secreções lácteas e constituintes do soro sanguíneo (GODDEN, 2008). A composição e as propriedades físicas do colostro bovino dependem de vários fatores, alguns já citados - como idade do animal e número de lactações - e outros como raça, nutrição e doenças concomitantes. Com o decorrer do tempo pós-parto, essa secreção láctea se altera e adquire novas características, passando a ser conhecida como leite (MADSEN et al., 2004; TSIOULPAS; GRANDISON; LEWIS, 2007). De forma consensual, o colostro é a secreção da glândula mamária da primeira ordenha após o parto (YANG et al., 2015). As secreções coletadas entre 24 a 72 horas pós-parto são denominadas leite de transição, devido ao fato de suas composições se assemelharem gradualmente à do leite (YANG et al., 2015). O colostro difere do leite quanto à sua composição, principalmente pelo elevado teor de proteínas totais $[14 \%$ com $6 \%(48 \mathrm{~g} / \mathrm{L})$ de Ig], sólidos $(23,9 \%)$ e gordura (6,7\%) (FOLEY; OTTERBY, 1978; KEHOE; JAYARAO; HEINRICHS, 2007). O leite de transição possui aproximadamente $15 \mathrm{~g} / \mathrm{L}(2,4 \%)$ de Ig, enquanto a secreção observada após 72 horas já é nomeada de leite e possui apenas 0,6g/L (0,09\%) de Ig (FOLEY; OTTERBY, 1978; KEHOE; JAYARAO; HEINRICHS, 2007; TSIOULPAS; GRANDISON; LEWIS, 2007).

Os anticorpos são os principais componentes do SIA presentes no colostro, que também possui todos os demais nutrientes essenciais para o desenvolvimento do neonato (STELWAGEN et al., 2009; VETTER et al., 2013). A classe de Ig mais abundante no colostro dos bovinos é a IgG com a concentração de $47,56 \mathrm{mg} / \mathrm{mL}$ e a predominância da subclasse IgG1. Quando da passagem do colostro para leite, a concentração cai para $0,59 \mathrm{mg} / \mathrm{mL}$, perfazendo $81 \%$ do total de Ig no colostro e de $73 \%$ do total de Ig no leite. A concentração de IgG2 no colostro é de $2,9 \mathrm{mg} / \mathrm{mL}$ e de $0,02 \mathrm{mg} / \mathrm{mL}$ no leite, com percentagens de $5 \%$ e $2,5 \%$, 
respectivamente. A IgA apresenta uma concentração de $3,9 \mathrm{mg} / \mathrm{mL}$ no colostro e de $0,14 \mathrm{mg} / \mathrm{mL}$ no leite, com percentuais de $7 \%$ e $18 \%$, respectivamente. Já a IgM apresenta uma concentração de $4,2 \mathrm{mg} / \mathrm{mL}$ no colostro e $0,05 \mathrm{mg} / \mathrm{mL}$ no leite, com percentuais de $7 \%$ e $6,5 \%$, respectivamente (GODDEN, 2008; STELWAGEN et al., 2009). Na avaliação dos fatores que interferem nos níveis de Ig no colostro de vacas sadias da raça Holandesa, foi observado que há maior concentração de IgG, IgA e IgM na primeira ordenha em relação à segunda ordenha (leite de transição). Entre as variações na concentração de Ig no colostro descritas entre raças de bovinos, tem sido observado que a raça Jersey apresenta maior concentração de IgG, IgM e IgA do que as raças Ayrshire, Guernsey, Pardo-Suíço e Holandês (MULLER; ELLINGER, 1981). Também foi demonstrado que, independente do grau de sangue, os animais mestiços Holandês-Zebu não apresentam diferenças significativas na concentração de IgG no colostro (SOARES FILHO et al., 2001).

As funções atribuídas às imunoglobulinas presentes no colostro incluem a prevenção de septicemias (IgM) e a imunidade intestinal contra os enteropatógenos (IgM e IgG1) (DAVIS; DRACKLEY, 1998). Para exercer as suas funções, as imunoglobulinas precisam ser protegidas contra a degradação proteolítica do trato gastrointestinal. Essa proteção ocorre por meio dos inibidores da tripsina presentes em altas concentrações no colostro, mas que diminuem rapidamente com a produção do leite, além disso, a atividade enzimática no trato digestivo no primeiro dia de vida é praticamente inexistente (DAVIS; DRACKLEY, 1998; GODDEN, 2008).

A concentração de Ig total no colostro é classificada como excelente $(>50 \mathrm{mg} / \mathrm{mL})$, moderada $(22$ a $50 \mathrm{mg} / \mathrm{mL})$ ou pobre $(<22 \mathrm{mg} / \mathrm{mL})$. O colostro a ser guardado congelado no banco de colostro deve ser de excelente qualidade para não ocasionar falhas na transferência de imunidade passiva, que ocorre quando a concentração de Ig total no soro dos animais em até dois dias pós-nascimento é menor que $10 \mathrm{mg} / \mathrm{mL}$ (GODDEN, 2008).

Entre os componentes celulares do colostro, observa-se que de $1 \times 10^{6}$ a $3 \times 10^{6}$ células $/ \mathrm{mL}$ são constituídas quase exclusivamente por leucócitos imunologicamente ativos, incluindo macrófagos ( $40 \%$ a $50 \%$ da concentração relativa), neutrófilos (25\% a $37 \%)$ e linfócitos (22\% a $25 \%)$ (LIEBLER-TENORIO; RIEDEL-CASPARI; POHLENZ, 2002; REBER; HIPPEND; HURLEY, 2005). A exposição continuada dos leucócitos a fatores inibitórios presentes no leite, como glóbulos de gordura e caseína, altera a sua morfologia e reduz a sua capacidade de fagocitose (PAAPE et al., 2003). A maioria dos linfócitos do colostro são linfócitos $\mathrm{T}$ com aproximadamente $5 \%$ do total de linfócitos da subpopulação de células B (CHASE; HURLEY; REBER, 2008; REBER; HIPPEND; HURLEY, 2005), que sobrevivem por até 36 horas no intestino dos bezerros recém-nascidos (TIZARD, 2013). Além disso, os valores relativos de células presentes no colostro parecem não diferir entre as ordenhas pós-parto, porém, na segunda ordenha há aumento do número absoluto de neutrófilos (GOMES et al., 2011).

As atribuições dos neutrófilos e macrófagos do colostro incluem a proteção contra bactérias devido à sua capacidade fagocítica, à produção intracelular de reativos de oxigênio, bem como à síntese de citocinas e peptídeos antimicrobianos (STELWAGEN et al., 2009). Adicionalmente, os leucócitos maternos ingeridos com o colostro são mais rápidos na estimulação das células apresentadoras de antígeno, essenciais para o desenvolvimento da resposta imune adquirida (CHASE; HURLEY; REBER, 2008). Riedel-Caspari (1993) observou que, no caso de infecções, a administração de colostro contendo linfócitos determinou rápido aumento das taxas de Ig específicas.

Componentes do sistema complemento, fatores de crescimento, hormônios, citocinas, oligossacarídeos, gangliosídeos, reativos de oxigênio, proteínas de fase aguda, fatores imunomoduladores, enzimas, ribonucleases, nucleotídeos, poliaminas, peptídeos e proteínas com atividade antimicrobiana, antioxidantes, inibidores de tripsina fazem parte da composição do colostro (ALBERA; KANKOFER, 2009; CHASE; HURLEY; REBER, 2008; GODDEN, 2008; MADSEN et al., 2004; STELWAGEN et al., 2009). Muitas de tais substâncias bioativas e promotoras do crescimento, presentes no colostro, influenciam o desenvolvimento do intestino do neonato. Os fatores de crescimento encontrados no colostro são o fator de crescimento transformante beta-2 (TGF- $\beta 2$ ), o hormônio do crescimento (GH), a insulina e o fator de crescimento semelhante à insulina 1 (IGF-1), que é um regulador do desenvolvimento do trato gastrointestinal dos bezerros (TIZARD, 2013). Essas substâncias estimulam o crescimento da mucosa, a secreção de enzimas, a síntese de ácido desoxirribonucleico (DNA) intestinal e o aumento do tamanho das vilosidades intestinais e da absorção de glicose (GODDEN, 2008).

As citocinas interleucina 1-beta (IL-1 $\beta$ ), IL-6, fator de necrose tumoral beta (TNF- $\beta$ ) e interferon gama (IFN- $\gamma$ ) do colostro, que estão principalmente associadas à resposta pró-inflamatória, também atuam no recrutamento de linfócitos para o intestino e proporcionam o desenvolvimento imunológico normal do órgão (YAMANAKA et al., 2003). Além disso, as citocinas também contribuem para o aumento da capacidade fagocítica dos neutrófilos e de outros fagócitos diante dos patógenos (CHASE; HURLEY; REBER, 2008). 
Os oligossacarídeos fornecem proteção contra os agentes infecciosos por meio da competição pela ligação aos receptores das superfícies epiteliais do intestino do neonato (GODDEN, 2008). Fatores antimicrobianos não específi$\cos$ - que incluem lactoferrina, lisozima, lactoperoxidase, proteína ligadora de lipopolissacarídeos e $\beta$-defensina (GODDEN, 2008; STELWAGEN et al., 2009), sintetizados pelo epitélio mamário bovino - também fazem parte dos componentes imunológicos do colostro (STELWAGEN et al., 2009). A lactoferrina, uma proteína que sequestra o ferro do meio, tem amplo efeito antimicrobiano contra diferentes bactérias, como Escherichia coli, Salmonella spp. e Staphylococcus spp. (JOSLIN et al., 2002). A administração de lactoferrina leva a aumento no ganho de peso diário dos bezerros, principalmente devido à melhora na saúde (JOSLIN et al., 2002).

Outro importante componente imunológico do colostro são os antioxidantes, que protegem o neonato contra o estresse oxidativo, o qual pode ocasionar danos celulares e geralmente ocorre durante e após o parto. Esses antioxidantes incluem: glutationa peroxidase, superóxido dismutase, catalase, lactoperoxidase, lactoferrina e ceruloplasmina (ALBERA; KANKOFER, 2009).

Além de o colostro fornecer componentes imunológicos, também é a primeira fonte dos nutrientes oferecidos aos bezerros neonatos. Ele contém proteínas, aminoácidos essenciais e não essenciais, ácidos graxos, lactose, vitaminas e minerais (MADSEN et al., 2004; SACERDOTE et al., 2013). A energia contida no colostro é de $1,16 \mathrm{Kcal} / \mathrm{g}$, aproximadamente o dobro da fornecida pelo leite (FONTES; COELHO; COSTA, 2007). A energia do colostro é fornecida pela gordura e lactose, configurando-se como essencial para a termogênese e regulação da temperatura corporal dos neonatos. Alguns minerais e vitaminas, incluindo cálcio, magnésio, zinco, manganês, ferro, cobalto, vitamina $A$, vitamina $\mathrm{E}$, caroteno, riboflavina, vitamina $\mathrm{B} 12$, ácido fólico e selênio, são encontrados em altas concentrações no colostro, quando comparado ao leite (GODDEN, 2008). Além desses elementos, o colostro contém uma série de fatores de crescimento, como o IGF-I e II, fator de crescimento epidermal e nervoso, insulina, cortisol e tiroxina (FONTES; COELHO; COSTA, 2007).

\section{Formação do colostro}

As secreções acumuladas na glândula mamária nas últimas semanas de gestação, juntamente com proteínas ativamente transferidas a partir da corrente sanguínea da vaca, vão formar o colostro (TIZARD, 2013). Esse processo ocorre devido à influência de hormônios, como estrógeno e progesterona, além de hormônios lactogênicos, como a prolactina (GODDEN, 2008; TIZARD, 2013). Fatores hormonais sistêmicos e locais são implicados no controle do transporte de imunoglobulinas durante a formação do colostro (GUY et al., 1994; HURLEY; THEIL, 2011). O sistema de regulação local, presente na glândula mamária, está relacionado à variação das concentrações de Ig e outros componentes do colostro encontrados entre os quartos mamários da mesma glândula e entre glândulas de diferentes vacas (BARRINGTON et al., 2001; BAUMRUCKER et al., 2010).

A maior porção de IgG do colostro provém do soro, enquanto pequena parte é produzida por plasmócitos pertencentes ao tecido mamário (HURLEY; THEIL, 2011). A migração desses plasmócitos para a glândula mamária é mediada por quimiocinas locais. Esse direcionamento é controlado principalmente pela expressão epitelial da quimiocina CCL28. As células secretoras de anticorpos expressam receptores CCR10 para essa quimiocina, permitindo a migração celular para o tecido mamário (STELWAGEN et al., 2009; WILSON; BUTCHER, 2004).

As concentrações de IgG1 diminuem no plasma materno a partir de duas a três semanas pré-parto (BAINTNER, 2007) e a sua concentração na glândula mamária atinge o pico um a três dias antes do parto (WEAVER et al., 2000), o que coincide com máxima concentração de IgG1 nas secreções lácteas (DELOUIS, 1978). O transporte seletivo de IgG para o colostro depende de dois mecanismos: a) presença de receptores específicos para IgG na membrana basal das células secretoras posicionados para capturar as moléculas ligantes a partir do fluido extracelular; b) capacidade de as células epiteliais mamárias realizarem a endocitose das moléculas de IgG, transportá-las em vesículas até a terminação apical da célula e liberá-las no lume alveolar em um processo chamado de transcitose (BARRINGTON et al., 2001; GODDEN, 2008; HURLEY; THEIL, 2011). Esses receptores estão presentes na superfície basolateral das células epiteliais alveolares e são específicos para a porção Fc das Ig (BARRINGTON et al., 2001; HURLEY; THEIL, 2011). Além do mecanismo descrito anteriormente, pequena parte das Ig pode entrar no colostro a partir do sangue, por uma via paracelular, através de junções intercelulares frouxas (STELWAGEN et al., 2009).

No caso da IgG, o receptor responsável pela transcitose é denominado FcRn, ou receptor Fc neonatal (HURLEY; THEIL, 2011; MAYER et al., 2005). Os FcRn dos mamíferos possuem papel central na maioria dos processos de absorção (MAYER et al., 2005). De forma geral, a expressão do FcRn é necessária para a distribuição dos anticorpos nos tecidos. Esse receptor, expresso em todas as idades e em vários tecidos, com diferentes níveis de expressão (BAINTNER, 2007), tem a sua expressão modulada pela 
prolactina (BARRINGTON et al., 1997). O FcRn é um heterodímero composto por uma cadeia a ligada à membrana, semelhante às moléculas do complexo principal de histocompatibilidade (MHC) de classe I (HURLEY; THEIL, 2011). A ligação da IgG ao FcRn é pH dependente, em pH ácido é de alta afinidade e em pH neutro a básico é fraca (BAINTNER, 2007). Ambientes ácidos estão em vesículas, vacúolos e endossomos de vários tipos de células. Dessa forma, as IgG, ao serem transportadas, ligam-se aos FcRn dos endossomos, onde o ambiente é ácido e, quando chegam ao lúmen da glândula mamária, onde o ambiente tende à neutralidade, a ligação torna-se fraca e ocorre a liberação da IgG a partir do FcRn (BAINTNER, 2007; HURLEY; THEIL, 2011; MAYER et al., 2005).

Durante a formação do colostro, até $500 \mathrm{~g}$ de IgG por semana são transferidas para as secreções mamárias (BARRINGTON et al., 2001), o que pode levar as vacas no pré-parto a apresentarem carência de Ig séricas e a desenvolverem alguns problemas ou patologias. No entanto, a IgG1 bovina se liga ao FcRn com elevada afinidade e é eficientemente secretada, enquanto a IgG2 apresenta pouca ligação. Essa diferença de afinidade e secreção das duas IgG garante a provisão adequada de imunoglobulinas para o bezerro neonato e protegem a vaca de excessiva depleção de anticorpos (BAINTNER, 2007).

As outras imunoglobulinas encontradas no colostro são IgA e IgM. A maior parte dessas imunoglobulinas é produzida localmente por plasmócitos da glândula mamária (HURLEY; THEIL, 2011), no entanto, uma parte das IgA e IgM é proveniente do sangue materno (TIZARD, 2013). O transporte transepitelial da IgA e IgM por meio das células do epitélio mamário ocorre via receptor de imunoglobulina polimérica (pIgR), que é responsável pela ligação à IgA dimérica e à IgM pentamérica (HURLEY; THEIL, 2011; STELWAGEN et al., 2009). As IgA e IgM ligadas aos pIgR são internalizadas e transportadas para a porção apical da célula epitelial mamária por um processo de endocitose (HURLEY; THEIL, 2011).

A expressão e regulação dos receptores envolvidos no transporte mamário de IgG e IgA parecem ser reguladas por mudanças endócrinas que ocorrem na proximidade do parto (STELWAGEN et al., 2009). Nesse período, as concentrações plasmáticas de estrógenos, progesterona, prolactina e corticoides mudam consideravelmente (DELOUIS, 1978). A progesterona e o estrógeno iniciam ou influenciam a atividade dos receptores de IgG1, essenciais para a produção do colostro. A redução da concentração de progesterona, que ocorre cerca de três semanas pré- parto, coincide com o início do processo de formação do colostro (BARRINGTON et al., 2001). Provavelmente, essa redução da relação progesterona/estrógeno no final da gestação, devido à redução da progesterona e ao aumento do estrógeno (GUY et al., 1994), seja o sinal para o início da transferência das IgG e da secreção do colostro (BARRINGTON et al., 2001). A progesterona por si só é incapaz de induzir essa secreção, mas pode potencializar o efeito estimulante do estradiol (DELOUIS, 1978).

O hormônio de crescimento bovino também participa da formação do colostro, possivelmente pelo aumento da vascularização da glândula mamária, com maior disponibilidade de IgG1 para ser captada (BARRINGTON et al., 2001). Em contraste, a cerca de uma semana do parto a concentração da prolactina, principal hormônio lactogênico, aumenta na circulação da vaca e promove uma redução da expressão e atividade dos receptores de IgG1 das células epiteliais alveolares, com consequente diminuição da secreção de IgG1 colostral (BARRINGTON et al., 1997; GODDEN, 2008). A concentração dos corticosteroides séricos também aumenta a partir de uma semana pré-parto e, juntamente com a prostaglandina F2 $\alpha$, eles contribuem para o início da secreção de leite e, portanto, contribuem para o término da secreção do colostro (BARRINGTON et al., 2001).

\section{Mecanismos de absorção de anticorpos e células}

A absorção intestinal das Ig colostrais pelos ungulados é transitória, não específica (HURLEY; THEIL, 2011) e dependente de alta concentração neonatal de corticosteroides. A administração de corticosteroides ou hormônio adrenocorticotrófico (ACTH) em bezerros neonatos prematuros aumenta a probabilidade de sobrevivência dos animais (CHASE; HURLEY; REBER, 2008; SANGILD, 2003).

Os enterócitos absorvem, de forma não seletiva, as proteínas e outras moléculas de alto peso molecular (WEAVER et al., 2000). Essas macromoléculas são transportadas e liberadas na lâmina própria e, então, absorvidas pela circulação linfática e portal (HURLEY; THEIL, 2011). Nos bezerros neonatos, a absorção do colostro pelas células intestinais acontece por dois mecanismos: endocitose e receptor neonatal FcRn (CHASE; HURLEY; REBER, 2008; MAYER et al., 2005). No nascimento, as células epiteliais do trato digestivo são permissivas à absorção das proteínas colostrais via pinocitose não seletiva (CHASE; HURLEY; REBER, 2008; GODDEN, 2008). Moléculas de Ig e outros constituintes do colostro são transportados através das células da mucosa intestinal e liberados na circulação linfática por exocitose e, então, transportadas pelos vasos linfáticos e pelo ducto torácico até a circulação sanguínea (GODDEN, 2008).

Evidências recentes sugerem que os receptores FcRn intermediariam a absorção de IgG por meio das barreiras celulares e protegeriam a IgG circulante do catabolismo 
(MAYER et al., 2005). Esses receptores já foram descritos em: glândula mamária, intestino delgado, rins e fígado. No intestino dos neonatos, os receptores FcRn e presentes na membrana da borda em escova dos enterócitos, que apresentam alta afinidade para se ligar às IgG ingeridas, dependem do $\mathrm{pH}$ ácido intestinal que está na porção proximal do intestino delgado dos mamíferos lactentes. Quando ocorre a ligação entre as moléculas, as IgG colostrais ficam protegidas das proteinases locais. Após a internalização do complexo FcRn-IgG e da transcitose em vesículas, as IgG são liberadas na linfa, que é levemente alcalina no lado basolateral dos enterócitos (BAINTNER, 2007).

A eficiência da transferência de Ig através do epitélio intestinal é máxima dentro das primeiras quatro horas pós-parto (GODDEN, 2008). À medida que o trato digestivo vai sendo estimulado pela ingestão de qualquer material, as células epiteliais, que permitem a absorção não seletiva de macromoléculas, vão sendo substituídas por células que não permitem a passagem de macromoléculas (CORTESE, 2009). Portanto, a capacidade absortiva intestinal do colostro começa a diminuir de $6 \mathrm{~h}$ a $12 \mathrm{~h}$ após o nascimento (CHASE; HURLEY; REBER, 2008; CORTESE, 2009). Não há consenso sobre quando as células intestinais perdem a capacidade de absorver macromoléculas intactas, entretanto, considera-se que isso ocorra entre $24 \mathrm{~h}$ a $36 \mathrm{~h}$ após o nascimento do bezerro (BAINTNER, 2007; CHASE; HURLEY; REBER, 2008; CORTESE, 2009; HURLEY; THEIL, 2011; MADSEN et al., 2004; SANGILD, 2003; WEAVER et al., 2000).

Ao menos uma porção dos leucócitos colostrais é absorvida intacta através da barreira intestinal (LIEBLERTENORIO; RIEDEL-CASPARI; POHLENZ, 2002; TUBOLY; BERNÁTH, 2002). Nos bezerros, a via preferencial para a absorção intestinal de leucócitos é através do epitélio associado aos folículos das placas de Peyer, no jejuno e no íleo (LIEBLER-TENORIO; RIEDEL-CASPARI; POHLENZ, 2002; TIZARD, 2013). Após entrar na circulação neonatal, os leucócitos maternos migram, via vasos linfáticos, para tecidos não linfoides e tecidos linfoides secundários, como os linfonodos mesentéricos (TUBOLY et al., 1995; TUBOLY; BERNÁTH , 2002). Evidências sugerem que, nos bezerros, esses leucócitos colostrais absorvidos aumentam a resposta dos linfócitos a mitógenos não específicos, o poder fagocítico e a habilidade de destruir bactérias, como também estimulam a resposta imune humoral (REBER; HIPPEND; HURLEY, 2005; RIEDELCASPARI, 1993; TUBOLY et al., 1995).

\section{Duração da imunidade passiva}

Os anticorpos maternos, absorvidos no intestino do neonato, alcançam concentrações máximas no soro $12 \mathrm{~h}$ a 24h após o nascimento (WEAVER et al., 2000). A partir de então, suas concentrações declinam lentamente por meio do catabolismo normal de proteínas. Os fatores primordiais que influenciam a duração da imunidade materna são a concentração e a meia-vida das Ig do colostro (BAINTNER, 2007; WILSON; BUTCHER, 2004). Esses dois fatores variam de acordo com o agente contra o qual as imunoglobulinas foram produzidas (TIZARD, 2013). A maioria dos anticorpos maternos bovinos tem uma meia-vida de 16 a 28 dias (BAINTNER, 2007; CHASE; HURLEY; REBER, 2008). De maneira geral, esses anticorpos conseguem proteger os bezerros por até três a quatro meses de idade (TIZARD, 2013).

A partir dessa idade, os bezerros podem e devem ser vacinados, com menor risco de interferência na resposta humoral pelas Ig maternas (TIZARD, 2013). Animais vacinados, na presença de altas concentrações de Ig maternas contra o antígeno vacinal, não apresentarão aumento dos níveis dessas Ig (CORTESE, 2009). O momento adequado para administrar vacinas em bezerros é quando a concentração de anticorpos maternos está baixa de modo a haver resposta imune ativa capaz de promover imunidade. Esse tempo pode variar de animal para animal e depende da concentração de anticorpos maternos e do antígeno vacinal em questão, podendo ser de poucas semanas a até oito meses de idade (CHASE; HURLEY; REBER, 2008).

\section{Considerações finais}

A grande importância do colostro para a sobrevida dos bezerros neonatos e as suas consequências na vida produtiva e reprodutiva desses animais é conhecida há muitos anos. A administração de quantidade correta de colostro de boa qualidade e o mais cedo possível é fator- chave para uma transferência de imunidade passiva tida como ideal, visto que somente nas primeiras horas de vida dos bezerros é que as suas células intestinais permitem a absorção de macromoléculas. Além disso, é relevante ressaltar que o colostro, além de muito rico em anticorpos e células, é também fonte de vários outros componentes imunológicos e nutricionais importantes para o desenvolvimento do animal. (1)

\section{Referências}

ALBERA, E.; KANKOFER, M. Antioxidants in colostrum and milk of sows and cows. Reproduction in Domestic Animals, Berlim, v. 44, n. 4, p. 606-611, 2009.

BAINTNER, K. Transmission of antibodies from mother to young: evolutionary strategies in a proteolytic environment. Veterinary Immunology and Immunopathology, Amsterdam, v. 117, n. 3-4, p. 153-161. 2007. 
BARRINGTON, G. M. et al. Effect of prolactin on in vitro expression of the bovine mammary immunoglobulin G1 receptor. Journal of Dairy Science, Champaign, v. 80, n. 1, p. 94-100. 1997.

BARRINGTON, G. M. et al. Regulation of colostrogenesis in cattle. Livestock Production Science, Amsterdam, v. 70, n. 1-2, p. 95104, 2001.

BAUMRUCKER, C. R. et al. Colostrogenesis: mass transfer of immunoglobulin G1 into colostrum. Journal of Dairy Science, Champaign, v. 93, n. 7, p. 3031-3038, 2010.

BESSER, T. E.; GAY, C. C.; PRITCHETT, L. Comparison of three methods of feeding colostrum to dairy calves. Journal of the American Veterinary Medical Association, Ithaca, v. 198, n. 3, p. 419-422, 1991.

BRANDON, M. R.; LASCELLES, A. K. Relative efficiency of absorption of $\operatorname{lgG} 1, \lg G 2, \lg A$ and $\lg M$ in the newborn calf. The Australian Journal of Experimental Biology and Medical Science, Adelaide, v. 49, n. 6, p. 629-633, 1971.

CHASE, C. C.; HURLEY, D. J.; REBER, A. J. Neonatal immune development in the calf and its impact on vaccine response. The Veterinary Clinics of North America: Food Animal Practice, Philadelphia, v. 24, n. 1, p. 87-104. 2008.

CORTESE, V. S. Neonatal immunology. The Veterinary Clinics of North America: Food Animal Practice, Philadelphia, v. 25, n. 1, p. 221-227, 2009.

DAVIS, C. L.; DRACKLEY, J. K. The development, nutrition, and management of the young calf. Ames: lowa State University Press. 1998. $339 \mathrm{p}$.

DELOUIS, C. Physiology of colostrum production. Annales de recherches vétérinaires, Paris, v. 9, n. 2, p. 193-203, 1978.

DIACOVICH, L.; GORVEL, J. P. Bacterial manipulation of innate immunity to promote infection. Nature Reviews: Microbiology, London, v. 8, n. 2, p. 117-28, 2010.

FOLEY, J. A.; OTTERBY, D. E. Availability, storage, treatment, composition, and feeding value of surplus colostrum: a review. Journal of Dairy Science, Champaign, v. 61, n. 8, p. 10331060, 1978.

FONTES, F. A. P. V.; COELHO, S. G.; COSTA, T. C. Efeitos da nutrição no sistema imune e na resistência a doenças. Revista Leite Integral, Belo Horizonte, v. 3, p. 3-30. 2007.

GEENEN, V. et al. Thymic T-cell tolerance of neuroendocrine functions: physiology and pathophysiology. Cellular and Molecular Biology, Noisy-le-Grand, v. 47, n. 1, p. 179-188, 2001.

GODDEN, S. Colostrum management for dairy calves. The Veterinary Clinics of North America: Food Animal Practice, Philadelphia, v. 24, n. 1, p. 19-39, 2008.

GOMES, V. et al. Dinâmica da celularidade do colostro de vacas da raça Holandesa no pós-parto imediato. Arquivo Brasileiro de Medicina Veterinária e Zootecnia, Belo Horizonte, v. 63, n. 5, p. 1047-1053, 2011.

GUY, M. A. et al. Regulation of colostrum formation in beef and dairy cows. Journal of Dairy Science, Champaign, v. 77, n. 10, p. 3002-3007, 1994.

HURLEY, W. L.; THEIL, P. K. Perspectives on immunoglobulins in colostrum and milk. Nutrients, Basel, v. 3, n. 4, p. 442-474, 2011. Disponível em <https://goo.gl/UNJTxx>. Acesso em: 1 ago. 2017.

JOSLIN, R. S. et al. Lactoferrin supplementation to dairy calves. Journal of Dairy Science, Champaign, v .85, n. 5, p. 12371242, 2002.

KEHOE, S. I.; JAYARAO, B. M.; HEINRICHS, A. J. A survey of bovine colostrum composition and colostrum management practices on Pennsylvania dairy farms. Journal of Dairy Science, Champaign, v. 90, n. 9, p. 4108-4016, 2007.

KINDT, T. J.; GOLDSBY, R. A.; OSBORNE, B. A. Kuby immunology. 6. ed. New York: W. H. Freeman, 2007. 574 p.

LIEBLER-TENORIO, E. M.; RIEDEL-CASPARI, G.; POHLENZ, J. F. Uptake of colostral leukocytes in the intestinal tract of newborn calves. Veterinary Immunology and Immunopathology, Amsterdam, v. 85, n. 1-2, p. 33-40, 2002.

MADSEN, B. D. et al. Physical properties of mammary secretions in relation to chemical changes during transition from colostrum to milk. The Journal of Dairy Research, London, v. 71, n. 3, p. 263272, 2004.

MAYER, B. et al. Expression of the neonatal Fc receptor ( $F C R n$ ) in the bovine mammary gland. The Journal of Dairy Research, London, v. 72, p. 107-112, 2005. Special Issue.

MULLER, L. D.; ELLINGER, D. K. Colostral immunoglobulin concentrations among breeds of dairy cattle. Journal of Dairy Science, Champaign, v. 64, n. 8, p. 1727-1730, 1981.

PAAPE, M. J. et al. The bovine neutrophil: struture and function in blood and milk. Veterinary Research, London, v. 34, n. 5, p. 597627, 2003.

PETER, A. T. Bovine placenta: a review on morphology, components, and defects from terminology and clinical perspectives. Theriogenology, Los Altos, v. 80, n. 7, p. 693705, 2013.

REBER, A. J.; HIPPEND. A. R.; HURLEY, D. J. Effects of the ingestion of whole colostrum or cell-free colostrum on the capacity of leukocytes in newborn calves to stimulate or respond in one-way mixed leukocyte cultures. American Journal of Veterinary Research, Schaumburg, v. 66, n.11, p. 1854-1860, 2005.

RIEDEL-CASPARI, G. The influence of colostral leukocytes on the course of an experimental Escherichia coli infection and serum antibodies in neonatal calves. Veterinary Immunology 
and Immunopathology, Amsterdam, v. 35, n. 3-4, p. 275288, 1993.

SACERDOTE, P. et al. Biological components in a standardized derivative of bovine colostrum. Journal of Dairy Science, Champaign, v. 96, n. 3, p. 1745-1754, 2013.

SANGILD, P. T. Uptake of colostral immunoglobulins by the compromised newborn farm animal. Acta Veterinaria Scandinavica, Copenhagen, v. 98, p. 105-122, 2003. Suplemento.

SOARES FILHO, P. M. et al. Concentrações de imunoglobulinas G em colostro de vacas mestiças holandês-zebu. Ciência Rural, Santa Maria, v. 31, n. 6, p. 1033-1037, 2001.

STELWAGEN, K. et al. Immune components of bovine colostrum and milk. Journal of Animal Science, Champaign, v. 87, n. 13, p. 3-9, 2009. Suplemento.

TASCHUK, R.; GRIEBEL, P. J. Commensal microbiome effects on mucosal immune system development in the ruminant gastrointestinal tract. Animal Health Research Reviews, Wallingford, v. 13, n. 1, p. 129-141, 2012.

TIZARD, I. R. Veterinary immunology. 9. ed. St. Louis: Elsevier Saunders, 2013. 551 p.

TSIOULPAS, A.; GRANDISON, A. S.; LEWIS, M. J. Changes in physical properties of bovine milk from the colostrum period to early lactation. Journal of Dairy Science, Champaign, v. 90, n. 11, p. 5012-5017, 2007.
TUBOLY, S.; BERNÁTH, S. Intestinal absorption of colostral lymphoid cells in newborn animals. Advances in Experimental Medicine and Biology, New York, v. 503, p. 107-114, 2002.

TUBOLY, S. et al. Intestinal absorption of colostral lymphocytes in newborn lambs and their role in the development of immune status. Acta Veterinaria Hungarica, Budapest, v. 43, n. 1, p. 105115, 1995.

VETTER, A. et al. Short communication: fractional milking distribution of immunoglobulin $G$ and other constituents in colostrum. Journal of Dairy Science, Champaign, v. 96, n. 9, p. 5919-5922, 2013.

WEAVER, D. M. et al. Passive transfer of colostral immunoglobulins in calves. Journal of Veterinary Internal Medicine, Philadelphia, v. 14, n. 6, p. $569-577,2000$.

WILSON, E.; BUTCHER, E. C. CCL28 controls immunoglobulin (Ig)A plasma cell accumulation in the lactating mammary gland and IgA antibody transfer to the neonate. The Journal of Experimental Medicine, New York, v. 200, n. 6, p. 805-809, 2004.

YAMANAKA, $\mathrm{H}$. et al. Proinflammatory cytokines in bovine colostrum potentiate the mitogenic response of peripheral blood mononuclear cells from newborn calves through IL-2 and CD25 expression. Microbiology and Immunology, Tokyo, v. 47, n. 6 , p. 461-468, 2003.

YANG, M. et al. Colostrum quality affects immune system establisment and intestinal development of neonatal calves. Journal of Dairy Science, Champaign, v. 98, n. 10, p. 7153-7163, 2015. 